\title{
ASSESSMENT OF BRONCHOALVEOLAR LAVAGE PEPSIN LEVEL IN IDIOPATHIC
} PULMONARY FIBROSIS

\author{
Ahmed Mohamed Said ${ }^{a,}$, Ahmed Mohamed Alsowey ${ }^{b}$, Hoda A. Ibraheem ${ }^{c}$ \\ ${ }^{a}$ Chest depatment, Zagazig University, Egypt \\ ${ }^{\text {b }}$ Radiodiagnosis department, , Zagazig University, Egypt \\ ${ }^{\text {c }}$ Clinical pathology department, , Zagazig University, Egypt
}

Corresponding author. Ahmed Mohamed Said Tel.: +20 01227308462 . E-mail address: kingarmstrong100@yah oo.com

\section{INTRODUCTION}

I diopathic pulmonary fibrosis (IPF) is the commonest cause of lung fibrosis[1]. There is a bad prognosis presented with a median survival rate $2-3$ years in patients probably diagnosed as IPF[2]. Unfortunately, no documented treatment for IPF was detected as the main causes are not known till now, despite the fact that numerous precipitating factors including smoking, viral infection, and gastroesophageal reflux (GER) with microaspiration have been declared [3].
There are many exciting purposes for detecting the relationship between GER, microaspiration and IPF. First, there is wide presentation of GER in IPF patients [4]. Second, age, smoking and male gender playing a role as a shearing risk factors in both IPF and GER [5]. It was declared that GER and microaspiration play a crucial role in pathogenesis of IPF, either by alteration in disease progression, acute exacerbation, or life span of these patients [6].

In many researches, it was detected that heartburn, regurgitation and dysphagia as 
common symptoms of GER aren't detected in many IPF patients. So, screening of abnormal GER in IPF patients by using the symptoms only is not appropriate method [7].

There is no accurate diagnostic testing for microaspiration and GER as declared by many researches. However by using of 24hour $\mathrm{pH}$ monitoring and/or impedance monitoring in diagnosis of presence or absence GER, but cannot emphasize presence of microaspirates [8].

The diagnosis of many aspiration events was reported in many barium swallow researches, but with limitations like aspiration must occur at the time of study and chronic microaspirates are not accurately detected[9]. One of more sensitive researches than barium swallow is pulmonary scintigraphy. However, more limitations presented that make it unused widely, like exposure to radiation and more expensive test [10]. Lastly, the valuable diagnosis of microaspiration was done by detecting the levels of bile acids and pepsin in Bronchoalveolar lavage (BAL)[11].

It was declared that pepsin and bile salt, acts as biomarkers of microaspiration specific to gastrointestinal tract (GIT), have been measured in respiratory tract. Normally there is no pepsin in lower respiratory tract and not always GER patients have elevated pepsin level in their BAL fluid[12].

Interestingly, the highly specific and sensitive method for diagnosing GER -associated with respiratory tract aspiration is measurement of pepsin level in BAL. Since the gold-standard for diagnosis of microaspiration remains undetected, so the assessment of pepsin and bile salt presence to the gastrointestinal tract makes this diagnostic technique incredibly attractive [13].

In general, adjusting the response of fibrogenesis after the injury is used mainly for recent treatment in IPF, not on prevention of injury itself. It was considered that microaspiration is a cause of frequent damage in idiopathic pulmonary fibrosis and may be controlled by medical and/or surgical therapy [3].

So, the objective of this study is to assess the presence of chronic microaspirates by measuring the pepsin level among idiopathic pulmonary fibrosis diagnosed patients with aiming at combining treatment of microaspiration with anti inflammatory and anti fibrotic agents, which may give a crucial combined approach for prevention of more injury to the lung from microaspiration and monitoring the deterioration of the disease in IPF patients.

\section{PATIENTS AND METHOD}

The current study was a case -control one conducted at Chest Department and outpatient clinics Faculty of Medicine, Zagazig University hospitals in the period from February 2013 till January 2016. Written informed consents were obtained from all patients.

\section{Patients:}

Sample size was 30 patients who selected randomly from stable interstitial lung diseases (ILD) attended to outpatient clinic and admitted at chest department for evaluation to be enrolled in this study.

Fifteen patients (group I) with stable idiopathic pulmonary fibrosis(IPF) were diagnosed according to high resolution computed tomography (HRCT) findings of usual interstitial pneumonia (UIP) and after exclusion of other known causes of ILD by history taking, clinical examination and blood tests for collagen vascular diseases and hepatitis $\mathrm{C}$ virus antibodies. This is according to the recently changed consensus criteria which made multiple explanation review for IPF as follows: it is a specific form of chronic, progressive fibrosing interstitial pneumonia of unknown cause, occurring primarily in older adults, limited to the lungs, and associated with the histopathologic and/or radiologic pattern of usual interstitial pneumonia (UIP) after exclusion of other forms of interstitial pneumonia including other idiopathic interstitial pneumonias and ILD associated with environmental exposure, medication, or systemic disease[14].

Another 15 patients (group II) with wellknown stable ILD other than IPF were included in this study as a control group. They were 3 patients with sarcoidosis, 4 patients with systemic lupus erythematosus, 3 patients with mixed connective tissue disease, and 5 patients with hypersensitivity pneumonitis. The Histopathological results and specific 
autoimmune markers were used for diagnosis of this group associated with the clinical and radiological picture of these patients.

\section{Exclusion criteria:}

IPF in acute exacerbation; defined by worsening of respiratory symptoms within 30 days, new bilateral ground glass opacities on HRCT, and no evidence of an alternative etiology [15].

\section{Methods:}

More than or equal to 30 days before starting the study, all patients had been requested to stop using acid suppressive therapy in form of proton pump inhibitors, $\mathrm{H} 2$ blockers and antacids.

All patients were submitted to:

1. Thorough medical history with stress on dyspnea scale [modified Medical Research Council (mMRC)] and symptoms of GER as regard to gastroesophageal reflux disease (GERD) questionnaire which consisted of six items, four positive predictors for GERD and two negative predictors [16].

\section{The four positive predictors are:}

- Heartburn.

- Regurgitation.

- $\quad$ Sleep disturbance because of these two reflux symptoms.

- The use of over-the-counter medication used in addition to that prescribed.

The two negative predictors are:

- $\quad$ Epigastric pain.

- Nausea.

2. Full clinical examination (general and local examination).

3. Chest X-ray (postero anterior and lateral views).

4. Arterial blood gases analysis (ABGs).

5. Coagulation profile (INR, PT, and PTT) was before doing bronchoscopy for all patients.

6. Blood tests for collagen vascular profile and HCV antibodies.

7. Spirometric ventilatory functions: was done by (wins piro PRO 5.0.0) and guided by the American Thoracic society (ATS) standards. If the lung volumes were $<80 \%$ of the predicted, the results were considered abnormal [17].
8. Pulmonary high resolution computed tomography (HRCT): it was done according to standard protocols to become aware of the abnormal radiological findings in IPF [14]. The images were evaluated blindly as regard to the clinical forms of all patients by a radiologist. The calculation semi quantitatively for pulmonary fibrosis severity in HRCT were done by measuring the percent of affected lung by fibrosis (i.e.reticular abnormality and/or honeycombing) to the nearest 5\% in three zones for each lung according to Best et al. [18]. The net radiological fibrosis score were done detecting the average numbers using a 4-point scale $(0=$ no involvement, $1=1-25 \%$ involvement, $2=26-50 \%$ involvement, $3=51-$ $75 \%$ involvement and $4=76-100 \%$ involvement) [19].

9. Bronchoscopy:

Premedication were taken to all studied patients (intravenous midazolam, and $4 \%$ lignocaine was applied topically to the nose, pharynx, and larynx). Besides, 4\% lignocaine was applied below the vocal cords in $1-\mathrm{ml}$ aliquots with maximum dosage $7 \mathrm{mg} / \mathrm{kg}$ body weight. Bronchoscopy was done with patients in a semi recumbent position through the nasal route. Oxygen supply was given and oxygen saturation monitored by oximetry [13]. Instillations of at least $100 \mathrm{ml}$ of sterile saline were done in a sub-segment of the right middle lobe or lingual for performing BAL. After that keeping BAL fluid on ice were done and processed within one hour of collection then frozen at $-80^{\circ} \mathrm{C}$. Measurements of total and differential cell counts in BAL fluid were done. Also, detection of pepsin in BAL fluid was done by using ELISA (USCNLife Science, Wuhan, China) [20].

\section{Statistical analysis}

Statistical analysis was performed with Epi Info_ version 7 and the SPSS version 19 statistical software package (SPSS Inc., Chicago, IL, USA). T test, the Chi-squared or Fisher's exact test and Binary logestic regression were used for comparing the differences in proportions. The correlation was calculated using Spearman's correlation coefficient by rank. P-value $<0.05$ was considered significant and $\mathrm{P}$-value $<0.01$ considered highly significant. 


\section{RESULTS}

Table (1) showed that this study included 30 patients with stable interstitial lung diseases (ILD) with mean age (62.6 \pm 3.3 years), 19 males and 11 females. They were divided into; 15 patients (group I) with stable idiopathic pulmonary fibrosis (IPF) with mean age (66.41 \pm 9 years), and Another 15 patients (group II) with well known stable ILD other than IPF with mean age $(57.70 \pm 6$ years). There was very high statistical significant difference between both groups as regard age $(\mathbf{p}<\mathbf{0 . 0 0 1})$.

The two groups were matched for sex and smoking habit $(\mathbf{P}>\mathbf{0 . 0 5})$, while a significant difference was detected between both groups as regard presence of GER symptoms $(\mathbf{p}<\mathbf{0 . 0 5})$. There was a statistically significant decrease in $\mathrm{PaO}_{2}, \mathrm{FEV}_{1} \%$ and $\mathrm{FVC}$ in (group I) than in (group II) $(\mathbf{p}<\mathbf{0 . 0 5})$.

Table (2) detected that there was a statistical significant increase in pepsin concentration, total cell count, neutrophils and red blood cells in bronchoalveolar lavage fluid among patients with stable IPF (group I) ,associated with a higher significant increase in alveolar macrophages at BAL fluid of (group I) patients comparing to patients in (group II) $(\mathbf{P}<\mathbf{0 . 0 5}$ and $\mathbf{p} \leq \mathbf{0 . 0 0 1}$, respectively).

Table (3) illustrated that increased reticulation on HRCT for IPF patients group were associated with higher BAL pepsin levels $(\mathbf{p}<\mathbf{0 . 0 1})$. Increased percentage of BAL lymphocytes was correlated with increased BAL pepsin level ( $\mathbf{p}<\mathbf{0 . 0 5})$, while there was a high negative correlation between FEV1\% and BAL pepsin levels (p < 0.01 ). Also, there were a negative correlation between BAL pepsin levels, $\mathrm{FVC} \%$ and $\mathrm{PaO}_{2}$ in IPF patients (group I) (p <0.05).

Table (4) showed the predictors of IPF severity. HRCT findings and BAL pepsin levels were the most powerful predictor while presence of GER symptoms was the least powerful one. Parameters were ordered according to the regression coefficient.

Table (1): Demographic and clinical characteristics and laboratory investigations of the studied groups.

\begin{tabular}{|c|c|c|c|c|}
\hline Parameter & $\begin{array}{l}\text { GroupI } \\
\text { No }=15\end{array}$ & $\begin{array}{c}\text { Group II } \\
\text { No }=15\end{array}$ & P-value & test \\
\hline & & & & $\mathbf{T}$ \\
\hline \multirow[t]{2}{*}{ Age (years) } & $66.41 \pm 9$ & $57.70 \pm 6$ & 0.00 & 3.12 \\
\hline & & & & $\chi^{2}$ \\
\hline Sex: Male/Female & $11 / 4$ & $8 / 7$ & 0.26 & 1.29 \\
\hline Smokers No. (\%) & $2(13.3 \%)$ & $1(6.7 \%)$ & 0.37 & 0.54 \\
\hline Ex-smokers & $7(46.7 \%)$ & $5(33.3 \%)$ & 0.56 & 0.46 \\
\hline \multicolumn{5}{|l|}{ Comorbidities } \\
\hline Coronary vascular disease & $4(26.66 \%)$ & $6(40.00 \%)$ & 0.44 & 0.06 \\
\hline Hypertension & $5(33.33 \%)$ & $7(46.66 \%)$ & 0.46 & 0.56 \\
\hline Diabetes Mellitus & $9(60.00 \%)$ & $8(53.33 \%)$ & 0.71 & 0.14 \\
\hline \multirow[t]{2}{*}{ GER symptoms No. ( \%) } & $12(80.0 \%)$ & $4(26.7 \%)$ & 0.00 & 8.57 \\
\hline & & & & $\mathbf{T}$ \\
\hline \multicolumn{5}{|l|}{ ABGs } \\
\hline pH & $7.38 \pm 0.02$ & $7.38 \pm 0.04$ & 1.73 & 0.09 \\
\hline $\mathrm{PaCO}_{2}(\mathrm{mmHg})$ & $32.7 \pm 6.8$ & $33.6 \pm 5.3$ & 0.45 & 0.66 \\
\hline $\mathrm{PaO}_{2}(\mathrm{mmHg})$ & $57.1 \pm 4.2$ & $61.5 \pm 3.4$ & 3.89 & 0.04 \\
\hline \multicolumn{5}{|l|}{ PFTs } \\
\hline $\mathrm{FEV}_{1}$ (\% pred.) & $43.7 \pm 11.3$ & $51.2 \pm 9.6$ & 2.22 & 0.03 \\
\hline FVC (\% pred.) & $44.3 \pm 10.5$ & $53.4 \pm 10.1$ & 2.15 & 0.04 \\
\hline Dyspnea scale (mMRC) & $2.8 \pm 0.6$ & $2.6 \pm 0.7$ & 1.26 & 0.22 \\
\hline
\end{tabular}

No= number, $\chi^{2}=$ Chi-squared test 
Table (2): Criteria of BAL fluid in the studied patients.

\begin{tabular}{|c|c|c|c|c|}
\hline Parameter & $\begin{array}{l}\text { Group I } \\
\text { No }=15\end{array}$ & $\begin{array}{l}\text { Group } \\
\mathrm{No}=15\end{array}$ & t test & P-value \\
\hline $\begin{array}{l}\text { Pepsin concentration }(\mathrm{ng} / \mathrm{ml}) \\
\text { mean } \pm \mathrm{SD} \text { (range) }\end{array}$ & $\begin{array}{c}43.7 \pm 11.4 \\
(20-87)\end{array}$ & $\begin{array}{l}32.7 \pm 10.5 \\
(15-53.2) \\
\end{array}$ & 2.86 & 0.04 \\
\hline $\begin{array}{l}\text { Total cell count cells } / \text { mL } \\
\text {-Neutrophils }(\text { mean } \pm \text { SD) } \\
\text {-Alveolar macrophages } \\
(\text { mean } \pm \text { SD) } \\
\text {-Lymphocytes }(\text { mean } \pm \text { SD) } \\
\text {-Esinophils }(\text { mean } \pm \text { SD) } \\
\text {-Red blood cells }(\text { mean } \pm \text { SD) }\end{array}$ & $\begin{array}{c}198.4 \pm 43.9 \\
28.3 \pm 4.7 \\
137.1 \pm 33.4 \\
29.1 \pm 7.8 \\
4.1 \pm 1.1 \\
95.7 \pm 29.2\end{array}$ & $\begin{array}{c}180.3 \pm 53.7 \\
13.1 \pm 2.7 \\
155.3 \pm 41.7 \\
24.5 \pm 8.4 \\
5.3 \pm 1.9 \\
68.7 \pm 22.3\end{array}$ & $\begin{array}{l}2.53 \\
2.64 \\
3.74 \\
1.75 \\
0.59 \\
2.85\end{array}$ & $\begin{array}{l}0.02 \\
0.01 \\
0.00 \\
0.09 \\
0.56 \\
0.01\end{array}$ \\
\hline
\end{tabular}

Table (3): Correlation analysis between bronchoalveolar lavage pepsin level and different studied parameters in stable IPF (group I) using spearman's rank correlation test.

\begin{tabular}{|c|c|c|}
\hline \multirow{2}{*}{$\begin{array}{c}\text { Group } \\
\text { Parameter }\end{array}$} & \multicolumn{2}{|c|}{$\begin{array}{c}\text { Stable IPF } \\
\text { (Group I) } \\
\text { No.= 15 }\end{array}$} \\
\hline & $\mathbf{r}$ & p-value \\
\hline $\begin{array}{l}\text { HRCT: } \\
\text { Reticulation score \% } \\
\text { Honeycombing score\% }\end{array}$ & $\begin{array}{l}0.57 \\
0.36\end{array}$ & $\begin{array}{l}<0.01 \\
>0.05\end{array}$ \\
\hline FEV1\% & -0.72 & $<0.01$ \\
\hline FVC\% & -0.59 & $<0.05$ \\
\hline $\mathrm{PaO}_{2}$ & -0.68 & $<0.05$ \\
\hline BAL lymphocytes & 0.56 & $<0.05$ \\
\hline BAL neutrophils & 0.07 & $>0.05$ \\
\hline BAL red blood cells & 0.13 & $>0.05$ \\
\hline BAL alveolar macrophages & 0.35 & $>0.05$ \\
\hline BAL esinophils & 0.13 & $>0.05$ \\
\hline \multicolumn{3}{|c|}{$\begin{array}{l}r=\text { correlation } \\
\text { Table (4): Regression analysis of significant predictors of IPF severity }\end{array}$} \\
\hline Variables value & Odds ratio $(95 \% \mathrm{CI})$ & P-value \\
\hline BAL pepsin level & $4.6(1.9-11.4)$ & $<0.001$ \\
\hline $\begin{array}{l}\text { HRCT: } \\
\text { Reticulation score \% } \\
\text { Honeycombing score\% }\end{array}$ & $\begin{array}{l}5.3(1.9-14.9) \\
7.8(2.7-22.3)\end{array}$ & $\begin{array}{l}<0.001 \\
<0.001\end{array}$ \\
\hline FEV $_{1} \%$ & $3.7(1.6-8.9)$ & 0.00 \\
\hline$\overline{\text { FVC\% }}$ & $3.2(1.4-7.5)$ & 0.00 \\
\hline $\mathrm{PaO}_{2}$ & $2.8(1.2-6.5)$ & 0.02 \\
\hline$\overline{\text { GER symptoms }}$ & $1.04(0.94-1.14)$ & 0.04 \\
\hline
\end{tabular}

CI: confidence interval 


\section{DISCUSSION}

Idiopathic pulmonary fibrosis (IPF) is a progressive disease characterized by chronic and irreversible interstitial pneumonia of unknown origin, which leads to lung fibrosis, respiratory failure, and finally death [21].

The role of hidden aspiration and gastroesophageal reflux in IPF patients became one of the crucial growing researches [3]. It was declared that hidden microaspiration was responsible for the progression and severity of IPF [22]. Besides, GERD was much more common among IPF patients than in patients suffering from cystic fibrosis, asthma, or chronic obstructive pulmonary disease [23].

So, the objective of this study is to assess the presence of chronic microaspirates by measuring the pepsin level among idiopathic pulmonary fibrosis diagnosed patients in BAL fluid.

As shown in Table (1), IPF patients were older in age than non IPF patients with very high statistical significant difference. Similarly Raghu and Meyer [24] concluded from their results of study that older patients were detected in IPF. Many studies declared that changes in gene expression or genetic polymorphisms which occur in older age were the commonest cause for injury and fibrosis of aged lung[25].

Poh et al. [26] concluded that elder patients are always associated with decrease gastroesophageal motion with decreasing in the pressure of the upper sphincter of the esophagus, and increasing exposure to acids in esophagus. Also, Patti et al. [27] detected that $60 \%$ of individuals presented with hiatal hernias older than 60 yrs in which oesophageal reflux and erosive oesophagitis were increased.

In the current study smoking habit was more common in IPF patients (group I) than in non IPF patients (group II) but without statistical significance. In concordance with Baumgartner et al. [28], they detected that one of most important risk factor for development of IPF was smoking with the odds ratio (OR) ranging from 1.6 to 2.9.from different parts in the world.

In our study GER symptoms were presented among $80 \%$ of IPF patients with statistical significant difference between two groups as shown in table (1). The same results were revealed by Sameh et al. [29], their results of study by comparing IPF patients with non IPF patients detected that in IPF patients group there was an increasing in the frequency of GER episodes. Also, in patients with IPF as regard the degree of pulmonary fibrosis and the severity of GER there was a significant correlation between them. However in non IPF patients, they didn't find any significant correlation between the severity of GER and the degree of lung fibrosis, which indicated that more damage and excessive fibrosis occurred in IPF diagnosed patients having more severe GER.

However, Sweet et al. [7] illustrated that 25-65\% was the range of the GER symptoms in their patients. They detected that the specificity of the presence of actual GER pathology was $71 \%$ for their patients. On the other hand Pilotto et al. [30] documented in their study that heart burn, epigastric discomfort and regurgitation were presented in GER and they detected the severity and frequency of symptoms, tend to become less in elderly which lead to the concept of "silent/occult GER and microaspiration".

However Locke [31] and Raghu et al. [32] observed from their studies, an apparent discordance between the prevalence of both GER and IPF diseases. They revealed this observation firstly, into variable degrees and duration of GER disease. Secondly, they clarified the presence of some other co-factor that pre-disposes to IPF pathogenesis such as (e.g. smoking, short telomere length, genetic predisposition). So, they confirmed that repeated aspiration in genetically susceptible patients could develop IPF.

Recently, the American Thoracic Society (ATS) guidelines had documented comprehensive, evidence-based perspective on the clinical importance of BAL cellular analysis in assisting and predicting nature of the ILD [33].

In the current study BAL fluid analysis as shown in table (2) revealed significant increase in pepsin concentration, total cell count, neutrophils and red blood cells in patients with stable IPF (group I), associated with a higher significant increase in alveolar 
macrophages. In concordance with Lee et al.[20] who found that there were pepsin in BAL of IPF patients. Moreover they concluded that BAL pepsin and neutrophil percentages were significantly increased in acute exacerbations of IPF. On the same way, Davis et al. [34] concluded from their study that BAL fluid pepsin levels were higher in IPF patients than in patients with COPD, $\alpha 1$ antitrypsin deficiency, or cystic fibrosis. Their study was based on measuring pepsin level in BAL fluid in 100 patients underwent lung transplantation.

As shown in table (3), a significant correlation was found between degree of lung fibrosis detected by HRCT and BAL lymphocytes with BAL pepsin level. This is in agreement with Lee et al. [20] which revealed that increasing both fibrosis on HRCT and lymphocytic counts in BAL fluid were associated with increased BAL pepsin level $(\mathbf{p}<\mathbf{0 . 0 1})$. While in our study there was a high negative correlation between FEV1\% and BAL pepsin levels in sable IPF group (p $<\mathbf{0 . 0 1})$. These results are in contrary with the results of Lee et al. [20], as they compared between exacerbated IPF and stable IPF groups and within the stable IPF, there was no correlation between BAL pepsin levels and percentage of predicted forced vital capacity (FVC) $(\mathbf{p = 0 . 3 9})$. The explanation for this different results is due to our stable IPF patients (group I) were more severe as regard pulmonary ventilatory function results than stable IPF patients in the previous study.

It was detected that HRCT findings in the form of reticulation score and honeycombing score, bronchoalveolar lavage pepsin level, $\mathrm{FEV}_{1} \%$ and FVC were the most powerful predictor of IPF severity. While a significant correlation was found as regard the severity of both pulmonary fibrosis and GER in patients diagnosed IPF, as GER symptom has[(Odds $\operatorname{ratio}(95 \% \mathrm{CI})=1.04(0.94-1.14)]$ which was the least powerful predictor as shown in table (4). These results are consistent with the results obtained by Savarino et al.[35]. In the same way Sameh et al.[29] enrolled that numbers of reflux episodes in proximal and distal part of esophagus were significantly correlate with the degree of lung fibrosis by HRCT scores in IPF diagnosed patients which insure the crucial role of GER in pulmonary fibrosis development and progression.

Recent researches illustrated that lung parenchymal pathology mostly increased due to continual microaspiration of gastric contents which play an important triggering mechanism. These results postulated that treatment of GER could improve clinical and functional parameters of IPF patients partially [36]. Besides, Lee et al.[37] who declared that using treatment for GER decreased the lung fibrosis in HRCT and also considered as an independent predictor of longer life span in IPF patients.

\section{CONCLUSION}

Gastroesophageal reflux or microaspiration is common in patients with IPF, associated with elevated levels of pepsin in BAL fluid. Besides, there is a high positive correlation between increased reticulation on HRCT and increased BAL pepsin level in IPF patients. Also, BAL pepsin level was the most powerful predictor in assessment of IPF severity.

\section{REFERENCES}

[1] G. Raghu, H.R. Collard, J.J. Egan, et al, An Official ATS/ERS/JRS/ALAT Statement: Idiopathic Pulmonary Fibrosis: Evidencebased Guidelines for Diagnosis and Management. Am J RespirCrit Care Med 183 (2011) 788-824.

[2] J.A. Bjoraker, J.H. Ryu, M.K. Edwin, et al, Prognostic significance of histopathologic subsets in idiopathic pulmonary fibrosis. Am J RespirCrit Care Med 157 (1998) 199-203.

[3] J.S. Lee, H.R. Collard, G. Raghu, et al, Does chronic microaspiration cause idiopathic pulmonary fibrosis? Am J Med. 123(2010) 304-311.

[4] G. Raghu, T.D. Freudenberger, S. Yang, et al, High prevalence of abnormal acid gastrooesophageal reflux in idiopathic pulmonary fibrosis.EurRespir J. 27 (2006)136-142.

[5] A. Sonnenberg, Effects of environment and lifestyle on gastroesophageal reflux disease. Dig Dis. 29(2011) 229-234.

[6] G. Raghu, Idiopathic pulmonary fibrosis: increased survival with "gastroesophageal reflux therapy":fact or fallacy? Am J RespirCrit Care Med. 184(2011) 1330-1332.

[7] M.P. Sweet, M.G. Patti, L.E. Leard, et al, Gastroesophageal reflux in patients with idiopathic pulmonary fibrosis referred for lung 
transplantation. J ThoracCardiovasc Surg. 133(2007) 1078-1084.

[8] R. Tutuian, Update in the diagnosis of gastroesophageal reflux disease. J Gastrointestin Liver Dis. 15(2006) 243-247.

[9] S.J. Stoeckli, T.A. Huisman, B. Seifert, et al, Interrater reliability of videofluoroscopic swallows evaluation. Dysphagia. 18(2003) 5357.

[10] A.M. Ravelli, M.B. Panarotto, L. Verdoni, et al, Pulmonary aspiration shown by scintigraphy in gastroesophageal reflux-related respiratory disease. Chest. 130(2006) 15201526.

[11] J.W. Ufberg, J.S. Bushra, D. Patel, et al, A new pepsin assay to detect pulmonary aspiration of gastric contents among newly intubated patients. Am J Emerg Med. 22(2004) 612-614.

[12] R. Stovold, I.A. Forrest, P.A. Corris, et al, Pepsin, a biomarker of gastric aspiration in lung allografts: a putative association with rejection. Am J Respir Crit Care Med 175(2007) 1298-303.

[13] S. Farrell, C. McMaster, D. Gibson, M.D. Shields, W.A. McCallion, Pepsin in bronchoalveolar lavage fluid: a specific and sensitive method of diagnosing gastrooesophageal reflux-related pulmonary aspiration. J Pediatr Surg. 41(2006) 289-93.

[14] G. Raghu, B. Rochwerg, Y. Zhang, C.A. Garcia, A. Azuma, J. Behr, et al, ATS, ERS, JRS, and ALAT. An Official ATS/ERS/JRS/ALAT Clinical Practice Guideline: treatment of idiopathic pulmonary fibrosis. An update of the 2011 Clinical Practice Guideline. Am J Respir Crit Care Med. 192(2) (2015) e3-e19.

[15] H.R. Collard, B.B. Moore, K.R. Flaherty, et al, Acute exacerbations of idiopathic pulmonary fibrosis. Am J RespirCrit Care Med 176(2007) 636-643.

[16] N. Vakil, S. Van Zanten, P. Kahrilas, et al, The montreal definition and classification of gastroesophageal reflux disease: a global evidence -based consensus . Am J Gastroenterol 101 (2006) 1900-1920.

[17] P.H. Quanjer, G.J. Tammeling, J.E. Cotes, et al, Lung volumes and forced ventilatory flows. Report working party standardization of lung function tests, European Community for Steel and Coal. Official Statement of the European Respiratory Society, Eur. Respir J. 6 (Suppl. 16) (1993) 5-40.

[18] A.C. Best, J. Meng, A.M. Lynch, et al, Idiopathic pulmonary Fibrosis; physiologic tests, quantitative $\mathrm{CT}$ indexes, and $\mathrm{CT}$ visual scores as predictors of mortality, Radiology 246 (2008) 935-940.

[19] D.A. Lynch, J.D. Godwin, S. Safrin, et al, HRCT in patients with idiopathic pulmonary fibrosis, Am. J. Respir. Crit. Care Med. 172 (2005) 488-493.

[20] J.S. Lee, J.W. Song, P.J. Wolters, et al, Bronchoalveolar lavage pepsin in acute exacerbation of idiopathic pulmonary fibrosis. EurRespir J 2012; 39: 352-358.

[21] E.A. Marco, R. Fabrizio, M. Mario, S. Francisco, G.P. Marco, Gastroesophageal Reflux and Idiopathic Pulmonary Fibrosis Internationale de Chirurgie.World J Surg. (2017) Mar 3. doi: 10.1007/s00268-017-39560

[22] J.S. Lee, The Role of Gastroesophageal Reflux and Microaspiration in Idiopathic Pulmonary Fibrosis.ClinPulm Med. 21(2) (2014) 81-85.

[23] K.C. Meyer, an Official American Thoracic Society Clinical Practice Guideline: The clinical utility of bronchoalveolar lavage cellular analysis in interstitial lung disease. Am J RespirCrit Care Med 185(2012) 1004-14.

[24] G. Raghu, K.C. Meyer, Silent gastrooesophageal reflux and microaspiration in IPF: mounting evidence for anti-reflux therapy? EurRespir J 39(2012) 242-245 DOI: 10.1183/09031936.00211311

[25] T.E. King, A. Pardo, M. Selman, Idiopathic pulmonary fibrosis. Lancet 378 (2011) 19491961.

[26] C.H. Poh, T. Navarro-Rodrigues, R. Fass, Review: treatment of gastroesophageal reflux disease in the elderly. Am J Med 123(2010) 496-501.

[27] M.G. Patti, H.I. Goldberg, M. Arcerito, et al, Hiatal hernia size affects lower esophageal sphincter function, esophageal acid exposure, and the degree of mucosal injury. Am J Surg 171 (1996) 182-186.

[28] K.B. Baumgartner, J. Samet, C.A. Stidley, Cigarette smoking: a risk factor for idiopathic pulmonary fibrosis, AJRCCM 155 (1997) 242248.

[29] E. Sameh, E.F. Salama, S.B. Ahmed, F.A. Ayman, Y.Y. Hala, Characteristics of gastroesophageal reflux in patients with idiopathic pulmonary fibrosis. Egyptian Journal of Chest Diseases and Tuberculosis 64 (2015) 505511

[30] A. Pilotto, M. Franceschi, G. Leandro, et al, Clinical features of reflux esophagitis in older people: a study of 840 consecutive 
patients. J Am Geriatr Soc 54 (2006) 15371542.

[31] G.R. Locke, 3rd. Current medical management of gastroesophageal reflux disease. ThoracSurgClin. 15(2005) 369-375.

[32] G. Raghu, D. Weycker, J. Edelsberg, et al, Incidence and prevalence of idiopathic pulmonary fibrosis. Am J RespirCrit Care Med. 174 (2006) 810-816.

[33]

Ammaiyappan,Chockalingam, Ranganatha

n,Duraiswamy, M. Jagadeesan,

Bronchoalveolar lavage cellular analyses in conjunction with high-resolution computed tomography imaging as a diagnostic intervention for patients with suspected interstitial lung disease. Lung India 33(3) (2016) 287-291. doi: 10.4103/09702113.180806

[34] C.S. Davis, B.M. Mendez, D.V. Flint, K. Pelletiere, E. Lowery, L. Ramirez , R.B.
Love, E.J. Kovacs, P.M. Fisichella, Pepsin concentrations are elevated in the bronchoalveolar lavage fluid of patients with idiopathic pulmonary fibrosis after lung transplantation J Surg Res. 185(2) (2013) e101-e108.. doi: 10.1016/j.jss.2013.06.011

[35] E. Savarino, R. Carbone, E. Marabotto, et al, Gastrooesophageal reflux and gastric aspiration in idiopathic pulmonary fibrosis patients, ERJ 42 (2013) 1322-1331.

[36] E. Savarino, M. Bazzica, P. Zentilin, et al, Gastroesophageal reflux and pulmonary fibrosis in scleroderma: a study using pHimpedance monitoring, Am. J. Respir. Crit. Care Med. 179(2009) 408-413.

[37] J.S. Lee, J.H. Ryu, B.M. Elicker, et al, Gastroesophageal reflux therapy is associated with longer survival in patients with idiopathic pulmonary fibrosis, Am. J. Respir. Crit. Care. Med. $184 \quad$ (2011) 1390-1394. 